La revue La revue pour l'histoire du CNRS

POUR LHISTORE DU CNRS $\quad 25 \mid 2010$

L'Aventure européenne du CNRS, I

Comment tremble la main invisible. Incertitude et marchés.

Éric Brian, Springer, 2009.

Bernard Valade

(2) OpenEdition

Journals

Édition électronique

URL : https://journals.openedition.org/histoire-cnrs/9254

DOI : 10.4000/histoire-cnrs.9254

ISSN : 1955-2408

Éditeur

CNRS Éditions

Édition imprimée

Date de publication : 15 octobre 2010

Pagination : 49

ISBN : 978-2-271-07114-9

ISSN : 1298-9800

Référence électronique

Bernard Valade, «Comment tremble la main invisible. Incertitude et marchés. », La revue pour l'histoire du CNRS [En ligne], 25 | 2010, mis en ligne le 15 octobre 2010, consulté le 20 mai 2021. URL : http:// journals.openedition.org/histoire-cnrs/9254; DOI : https://doi.org/10.4000/histoire-cnrs.9254

Ce document a été généré automatiquement le 20 mai 2021.

Comité pour l'histoire du CNRS 


\section{Comment tremble la main invisible. Incertitude et marchés.}

Éric Brian, Springer, 2009.

\section{Bernard Valade}

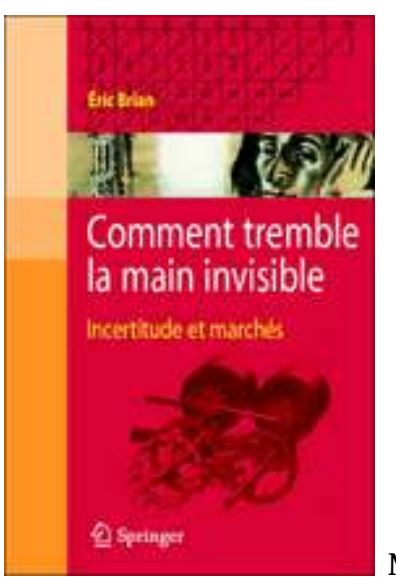

Montrer que la main invisible ne peut que trembler et marquer le primat d'une épistémologie de l'incertitude sur la codification des lois économiques, tel est l'objectif de cet ouvrage où le retour sur l'histoire du calcul des probabilités croise des questions d'actualité : les dysfonctionnements de la machine de crédit et le désordre des marchés financiers. D'une concision (moins de 200 pages) qui n'a d'égale que sa densité, le propos développé, jalonné de figures, de tableaux, de formules, est à double entrée - philosophique et sociologique, économique et financière. Il renouvelle la réflexion sur les fondements stochastiques des phénomènes économiques, en congédiant l'objectivisme, le formalisme et les abstractions de l'homo oeconomicus; en associant aussi économie et sociologie, modèles et enquêtes, calcul et institutions, comme l'a précédemment fait l'auteur dans La Mesure de l'État (1994).

1 Au seuil de cette nouvelle étude, il nous est rappelé que « le hasard, l'imprévisibilité, l'incertitude viennent avant le calcul, et non après ", ce dont procède l'opposition entre le raisonnement statistique, qui fait du hasard un résidu, et le raisonnement stochastique, pour lequel l'incertitude est constitutive de l'ensemble des phénomènes. Une série de distinctions sont ensuite introduites, entre incertitude et probabilité 
subjectives d'une part, probabilité et incertitude des phénomènes d'autre part, et leur intégration est opérée dans un cadre épistémologique général. Ce dernier est solidaire d'une périodisation qui fait se succéder, $d u X V I I^{e}$ au $X X X^{e}$ siècle, les réponses à l'incertitude économique, en liaison avec les biens types (rentes, marchandises, actifs), les critères de réglage collectifs du marché (arbitrage, moyenne, martingale), les différents régimes du calcul des probabilités (classique, analytique, axiomatique). Reprenant les remarques de Christian Walter sur la recherche des martingales en matière de marchés qui a abouti à une "martingalisation » systématique des variations boursières, de la même façon qu'au XIX ${ }^{\mathrm{e}}$ siècle, la recherche de moyennes a conduit à une « moyennisation » systématique des variables, Éric Brian souligne que ce processus a engendré un paradigme différent de celui que Quetelet nous a légué dans ses Lettres sur la théorie des probabilités appliquée aux sciences morales et politiques (1846). Il en résulte la nécessité d'un déplacement de la perspective épistémologique et la proposition de constructions alternatives, au moyen des lois Pareto / Levy introduites dans la théorie mathématique financière par B. Mandelbrodt.

2 L'emprise sur le raisonnement économique de la statistique de "l'homme moyen ", polarisée sur la tendance centrale et les fluctuations régies par une distribution Laplace / Gauss, n'en persiste pas moins. É. Brian tire les conséquences, y compris sur le plan de la spéculation, de cette fétichisation de la moyenne qui détourne l'attention des extrêmes. Mais son dessein, comme il l'explique (p.70,151, 157), n'est pas de substituer un modèle à un autre ; il vise la « mise en œuvre concrète » d'un schéma explicatif, avec l'insertion de la théorie de l'action rationnelle dans un cadre d'analyse «où les conditions de possibilités des actions sont gouvernées par des combinaisons changeantes de ressources, d'institutions et de calculs ». D'où l'importance des vérifications empiriques effectuées, de la prise en compte des structures temporelles de l'incertitude financière - avec la distinction cruciale d'un référentiel calendaire (temps de l'horloge) et d'un référentiel séquentiel (rythme des transactions) - et aussi du recours aux notions d'" attente collective", d'" escompte de l'avenir " naguère conceptualisées par Marcel Mauss. Cette démonstration, que soutient une base documentaire véritablement interdisciplinaire, s'accompagne d'illustrations aussi piquantes qu'originales, comme celles de la section intitulée «Perette paretienne » où trois fables de La Fontaine, Le Petit Poisson et le Pêcheur, Le Savetier et le Financier, La Laitière et le Pot au lait, fournissent une palette de formes idéales-typiques de probabilités subjectives.

\section{AUTEUR}

\section{BERNARD VALADE}

Historien des idées, Paris V-Sorbonne. 